\title{
Antisense inhibition of ATM gene enhances the radiosensitivity of head and neck squamous cell carcinoma in mice Jian Zou ${ }^{\dagger 1,2}$, Xiaoming Qiao ${ }^{\dagger 1}$, Huiping Ye ${ }^{1}$, Yuqiong Yang ${ }^{3}$, Xuelian Zheng ${ }^{2}$, Houyu Zhao ${ }^{1}$ and Shixi Liu*1,2
}

\author{
Address: ${ }^{1}$ Department of Otolaryngology, West China Hospital, Sichuan University, Chengdu, 610041, PR China, ${ }^{2}$ State Key Laboratory of \\ Biotherapy, West China Hospital, Sichuan University, Chengdu, 610041, PR China and ${ }^{3}$ Department of Oncology, West China Hospital, Sichuan \\ University, Chengdu, 610041, PR China \\ Email: Jian Zou - zoujian926@gmail.com; Xiaoming Qiao - xmqiaoent@gmail.com; Huiping Ye - yehuiping888@yahoo.com.cn; \\ Yuqiong Yang - westhuaxi@163.com; Xuelian Zheng - schoolhua@yahoo.cn; Houyu Zhao - chengduent@sohu.com; \\ Shixi Liu* - liushixi999@gmail.com \\ * Corresponding author †Equal contributors
}

Published: 26 October 2008

Journal of Experimental \& Clinical Cancer Research 2008, 27:56 doi:10.1 186/1756-9966-27-56

This article is available from: http://www.jeccr.com/content/27/I/56

(C) 2008 Zou et al; licensee BioMed Central Ltd.

This is an Open Access article distributed under the terms of the Creative Commons Attribution License (http://creativecommons.org/licenses/by/2.0), which permits unrestricted use, distribution, and reproduction in any medium, provided the original work is properly cited.
Received: 25 August 2008

Accepted: 26 October 2008

\begin{abstract}
Background: Treatment failure after radiotherapy of head and neck squamous cell carcinoma (HNSCC) could be a significant problem. Our objective is to sensitize SCCVII cells to ionizing radiation in vitro and in vivo through inhibiting ATM expression using antisense oligodeoxynucleotides (AS-ODNs), and investigate the potential mechanism of radiosensitization.

Methods: We designed and synthesized AS-ODNs that target ATM mRNA to reduce the ATM expression. The influence on the expression of ATM mRNA and protein in SCCVII cells were analysed by real-time quantitative PCR and western blotting respectively. Clonogenic survival assay was performed to detect the survival ability of SCCVII cells after irradiation, while flow cytometry used to analyse the cell cycle and apoptosis. The volume of solid tumors generated with SCCVII cells was measured, and cell apoptosis was analysed by TUNEL assay after irradiation.
\end{abstract}

Results: The relative ATM mRNA and protein expression in SCCVII cells treated with ATM ASODNs were decreased to $25.7 \pm 3.1 \%$ and $24.1 \pm 2.8 \%$ of that in untreated cells respectively $(P<$ 0.05). After irradiation, the survival fraction (SF) of cells treated with ATM AS-ODNs was lower than that of other groups at the same dose of radiation $(P<0.05)$, while the percentage of cells in $\mathrm{G} 2 / \mathrm{M}$ phase decreased and apoptotic rate of cells increased $(P<0.05)$. The inhibition rate in SCCVII cells solid tumor exposed to $X$-ray alone was $23.2 \pm 2.7 \%$, while it was $56.1 \pm 3.8 \%$ in the group which irradiated in combination with the treatment of ATM AS-ODNs $(P<0.05)$. The apoptotic index for the group irradiated in combination with ATM AS-ODNs injection was $19.6 \pm 3.2$, which was significantly higher than that of others $(P<0.05)$

Conclusion: Inhibition of ATM expression sensitized SCCVII cells to ionizing radiation in vitro and in vivo. The potential mechanism should be the defective G2/M cell cycle checkpoint control and enhanced radiation-induced apoptosis. 


\section{Background}

Despite advances in surgical treatments, radiotherapy is superior in its ability to preserve function and appearance in the treatment of head and neck squamous cell carcinoma (HNSCC). But some kinds of HNSCC are refractory to ionizing radiation, which results in the low effectiveness of radiotherapy alone[1,2]. SCCVII cell line, is a spontaneously arising head and neck squamous carcinoma cell line from syngeneic $\mathrm{C} 3 \mathrm{H} / \mathrm{HeJ}$ mice[3]. An oral cancer murine model using the SCCVII cell line shares characteristics such as initial locoregional tumor invasion, direct extension into the neck, and early cervical metastases with human head and neck tumors[4]. So SCCVII cell line could be a good object to study the biological behavior of HNSCC.

One strategy to improve the effectiveness of radiotherapy is augmenting of tumour radiosensitivity[5]. In the latter study, SCCVII cells were found to be resistant to ionizing radiation. The cytotoxicity of ionizing radiation is mainly mediated through the generation of DNA-double strand break (DSB) as evidenced by the pronounced radiosensitivity of cells and organisms defective in the machinery of DSB repair[6-8]. Thus, inhibition of DSB repair provides a mechanism to enhance the cytotoxicity of IR in tumour cells. The ataxia-telangiectasia mutated (ATM) protein kinase is a critical component in these pathways and integrates the cellular response to damage by phosphorylating key proteins involved in cell cycle regulation and DSB repair[9,10]. Lack of the normal ATM function in the inherited ataxia telangiectasia (AT) syndrome results in the profound hypersensitivity to ionizing radiation[1113]. As mentioned elsewhere p53-wild-type cell lines with dysfunctional ATM, when irradiated, either show a lack of or delayed activation of p53, resulting in a defective G1/S cell-cycle checkpoint[14]. However, in p53 mutated cell lines, disruption of ATM resulted in defective G2/M checkpoint control, radio-resistant DNA synthesis, retarded cell proliferation and enhanced radiosensitivity $[15,16]$. Therefore, we manage to examine whether reduction of ATM expression after antisense oligodeoxynucleotides (AS-ODNs) treatment would result in enhanced radiosensitivity of p53-mutated SCCVII cells from $\mathrm{C} 3 \mathrm{H} / \mathrm{He}$ mice through the aberrant G2/M checkpoint.

\section{Methods \\ Reagents}

RPMI-1640 media and 10\% heat-inactivated fetal bovine serum (FBS) were purchased from Gibco Company (Eggenstein, Germany). Lipofectamine 2000, Opti-MEM medium and Trizol kit were bought from Invitrogen Company(Carlsbad, CA, USA). SYBR ExScript RT-PCR Kit and SYBR Green Master Mix were purchased from Takara Biotechnology Company (Dalian, China). ATM monoclonal antibodies was bought from Santa Cruz Biotechnology
(Santa Cruz, CA, USA), and $\beta$-actin monoclonal antibodies from Sigma (St Louis, MO, USA). BCIP/NBT alkaline phosphatase substrate kit IV was purchased from Vector laboratories (Burlingame, CA, USA). TUNEL apoptosis detection kit was bought from Roche Company (Shanghai, China)

\section{Cell lines and mice}

SCCVII cell line was generously obtained from the laboratory of gene therapy at Johns Hopkins University. SCCVII cells were cultured in complete RPMI-1640 media containing 10\% heat-inactivated FBS, 2 mM L-glutamine, 100 $\mathrm{IU} / \mathrm{mL}$ penicillin, $100 \mu \mathrm{g} / \mathrm{mL}$ streptomycin. Cells were cultured as a monolayer at $37^{\circ} \mathrm{C}$ in a humidified atmosphere containing 5\% CO2. Female $\mathrm{C} 3 \mathrm{H} / \mathrm{He}$ mice, aged 68 weeks, weighing 18-22 g, were obtained from Vital River Laboratories (Beijing, China) and were maintained in the animal facility at West China Medical School, Sichuan University in accordance with nation's related regulations and animal welfare requirements.

\section{Synthesis of oligodeoxynucleotides(ODNs) and selection of target sequences}

A 25-mer AS-ODN which was previously reported to inhibit ATM expression in mouse cerebrovascular endothelial cells[17], and its associated controls, sense (Sen) and mismatch (Mis) ODNs, were synthesized by Shanghai Sangon Biological Engineering Technology \& Services (Shangai, China). The sequences were as follows: AS, 5'-GTGCTAGACTCATGGTTTAAGATTT-3'; Sen, 5'AAATCTTAAACCATGAGTCTAGCAC-3' and Mis, 5'CCCCAGCAGCTCCCATTGGGCGTAA-3'. All the ODNs were chemically modified to phosphorothioate ODNs by substituting the oxygen molecules of the phosphate backbone with sulfur.

\section{Transfection of ODNs in SCCVII cells}

SCCVII cells at a density of $5 \times 10^{4}$ cells $/ \mathrm{ml}$ were plated for overnight incubation. Cells were maintained in RPMI1640 medium supplemented with $10 \%$ FBS at $37^{\circ} \mathrm{C}$ and $5 \%$ CO2. After grew to $80 \%-90 \%$ fill, cells were replenished with incompleted RPMI-1640 medium, then treated with ATM AS-ODNs, ATM Sen-ODNs and Mis-ODNs. The procedures were as follows: $200 \mathrm{nM}$ of ATM AS-ODNs, Sen-ODNs, Mis-ODNs and $2 \mathrm{mg} / \mathrm{ml}$ Lipofectamine 2000 were added to Opti-MEM medium separately, and incubated for $5 \mathrm{~min}$ at room temperature. Then liposome and ODNs were mixed together respectively and incubated at room temperature for $20 \mathrm{~min}$. SCCVII cells were washed again with Opti-MEM medium before transfection. The liposome ODNs complexes were carefully plated on the cells, and incubated at $37^{\circ} \mathrm{C}, 5 \% \mathrm{CO} 2$. After 6 hours transfected cells were washed twice with PBS, the medium was replaced with fresh RPMI-1640 medium supplemented with $10 \%$ FBS, cells were incubated at $37^{\circ} \mathrm{C}$ overnight. A 
second ODNs incubation was performed before cells were exposed to radiation.

\section{Real-time quantitative $P C R$ analysis}

Total RNAs were extracted from cultured SCCVII cells using Trizol reagent according to the manufacture's protocol. RNA concentration and purity were determined on a UV spectrophotometer (BioRad Inc., Hercules, CA, USA) by the $260 \mathrm{~nm}$ absorbance and $260-280 \mathrm{~nm}$ absorbance ratio, respectively. Synthesis of cDNA was conducted using SYBR ExScript RT-PCR Kit according to manufacturer's instructions. Real-time quantitative RT-PCR for the ATM mRNA was performed on an ABI PRISM 7300 Sequence Detection System (Applied Biosystems, Foster City, CA, USA) using SYBR Green Master Mix. For normalization the gene GAPDH was used. Final reaction volume is $25 \mu$ l. Cycling conditions were as follows: initial denaturation at $95^{\circ} \mathrm{C}$ for $10 \mathrm{~s}$, followed by 40 cycles of $95^{\circ} \mathrm{C}$ for $5 \mathrm{~s}$ and $59^{\circ} \mathrm{C}$ for $31 \mathrm{~s}$. Each measurement was performed in triplicate. The gene expression levels obtained were normalized by mRNA expression of GAPDH. The relative mRNA expression was then presented in relation to the untreated control group. All oligonucleotide primers were designed and synthesized by Sangon (Shanghai, China). The primer sequences are listed as follows: ATM, forward, 5'-CCAGGGGAAGATGATGAAGA-3' reverse 5'CTACAATGAGCTGCGTGTGG-3'; GAPDH, forward,5'CCTCAAGATTGTCAGCAAT-3' reverse, 5'-CCATCCACAGTCTTCTGAGT-3'.

\section{Western blot analysis}

Total proteins extracted from SCCVII cells were separated on $10 \%$ or $15 \%$ SDS-polyacrylamide gels. Fifty micrograms each of the preparations were fractionated by $12.5 \%$ SDS-PAGE and transferred to nitrocellulose membrane (Millipore, Bedford, MA). The membrane was blocked with 3\% milk powder in PBS at room temperature for 3 hours, washed with TBS (PBS containing 0.1\% Tween-20) for 10 min three times, then incubated with the ATM monoclonal antibodies (1:1000 dilution) or $\beta$ actin monoclonal antibodies (1:2000 dilution) in TBS containing $1 \%$ milk powder at $4{ }^{\circ} \mathrm{C}$ overnight. After three washes with TBS, the membrane was incubated with alkaline phosphatase-labeled anti-mouse IgG antibody in TBS containing $1 \%$ milk powder at room temperature for 3 hours and washed again with TBS three times. The membrane was briefly equilibrated with PBS and visualized with the BCIP/NBT alkaline phosphatases substrate kit IV. Reactive bands were scanned by Gel Doc 1000 (Bio-Rad). The experiment was repeated three times.

\section{Irradiation}

ELEKTA Precise radiation system (Elekta, Sweden) was used to irradiate cells and solid tumor. X-ray irradiation was performed at room temperature at a dose rate of 200
cGy/min and equipped with an external 0.5-mm copper filter.

\section{Clonogenic survival assay}

The SCCVII cells were seeded in triplicate at limiting dilutions in 6-well plates for about 24 hours in RPMI- 1640 medium supplemented with $10 \%$ FBS until attached. Then the cells were transfected with ATM AS-ODNs, ATM Sen-ODNs and Mis-ODNs respectively. About 18 hours after transfection, they were irradiated with different doses of X-ray radiation $(0,2,4,6$, and $8 \mathrm{~Gy})$ respectively. The medium was replaced with a fresh one 24 hours after irradiation. After 7 days of incubation, the colonies were fixed with methanol, stained with $0.5 \%$ crystal violet in absolute ethanol and colonies with $>50$ cells were counted under dissection microscope. In each irradiation dose group, surviving fraction (SF) of cells was calculated as plating efficiency of the irradiated cells divided by the plating efficiency of the irradiated cells by that of the untreated control.

\section{Cell cycle and apoptosis analyzed by flow cytometry}

After 48 hours exposed to 2 Gy radiation, cells were harvested, and centrifuged at $1500 \mathrm{rpm}$ for $2 \mathrm{~min}$. Then cells were washed with PBS twice, and fixed with $70 \%$ icy-cold ethanol at $4{ }^{\circ} \mathrm{C}$ overnight. Cells were stained with PI at $4^{\circ} \mathrm{C}$ for $30 \mathrm{~min}$. Cell cycle progression and apoptotic rate were analyzed by flow cytometry (Elite ESP, Beckman Coulter, USA).

\section{Animal experiment of radiosensitization}

Female $\mathrm{C} 3 \mathrm{H} / \mathrm{He}$ mice were used to investigate the effect of ATM AS-ODNs on radiosensitivity of SCCVII cells solid tumor. All surgical procedures and care administered to the animals were in accordance with institutional guidelines. Animal surgeries and radiotherapy were performed under general anesthesia, $50 \mathrm{mg} / \mathrm{kg}$ ip injection of pentobarbital sodium. About $5 \times 10^{6}$ SCCVII cells were subcutaneously inoculated in submental space of the mice. Tumor growth rates were determined by measuring two orthogonal dimensional diameters of each tumor twice a week. Tumour volumes were estimated according to the formula $\mathrm{V}=\pi / 6 \times \mathrm{a} 2 \times \mathrm{b}$, where $\mathrm{a}$ is the short axis, and $\mathrm{b}$ the long axis. When tumors reached an average volume of about $200 \mathrm{~mm}^{3}$, the tumor-bearing $\mathrm{C} 3 \mathrm{H} / \mathrm{He}$ mice were divided into four groups: (a) control group, no treatment; (b) ATM AS-ODNs group, tumors were treated with ATM AS-ODNs alone but not exposed to irradiation for each time; (c) irradiation group, tumors were exposed to X-ray of 2 Gy alone for each time; and (d) combination group, $2.5 \mathrm{mg} / \mathrm{kg}$ of ATM AS-ODNs was injected into the solid tumor the day before X-ray exposure, another dosage of ATM AS-ODNs was injected right before exposure to 2 Gy of X-ray for each time. The same treatment for each group were repeated 3 times (the interval time was 5 days). $\mathrm{C} 3 \mathrm{H} /$ 
He mice were killed 3 weeks later. The ATM protein expression of the tumor in the different groups were ananlysed by western blot using the procedures described as above. The tumor inhibition rate was evaluated using the following formula: (1-average tumor volume of experimental group/average tumor volume of control group) $\times$ $100 \%$.

\section{Terminal deoxynucleotidyltransferase-mediated dUTP- digoxigenin nick-end-labeling (TUNEL) assay}

TUNEL staining of tumour sections was performed using an in situ apoptosis detection kit (Roche, Shanghai, China) according to the manufacture's protocol. The total number of apoptotic cells in 10 randomly selected fields was counted. The apoptotic index (AI) was calculated as the percentage of positive staining cells, namely $\mathrm{AI}=$ number of apoptotic cells $\times 100 /$ total number of nucleated cells.

\section{Statistics}

Results were expressed as mean \pm standard deviation(SD). SPSS12.0 software package was used to perform statistical analysis. One-way ANOVA test was used to determine statistical difference between the experimental groups with others. Differences were considered statistically significant at $P<0.05$.

\section{Results \\ Expression of ATM in ATM AS-ODNs transfected SCCVII cells}

We analyzed the expression of ATM in mRNA and protein level in SCCVII cells using real-time fluorescent quantitative PCR and western blot assay respectively. After 48 hours treatment, there were no significant difference among the group treated with liposome alone, the group treated with Sen-ODNs and the group treated with MisODNs $(P>0.05$; Figure. 1$)$. However when incubating with liposome formulations of ATM AS-ODNs, the relative ATM mRNA expression was only about $25.7 \pm 3.1 \%$ to the untreated SCCVII cells, which demonstrated a significantly reduced expression of ATM mRNA $(P<0.05$; Figure. 1). As shown in Figure. 2, ATM protein expression was also significantly reduced by ATM AS-ODNs compared with Sen-ODNs and Mis-ODNs after 72 hours treatment (Figure. 2A). The relative ATM protein expression of SCCVII cells treated with ATM AS-ODNs was only about $24.1 \pm 2.8 \%$ to the untreated cells $(P<0.05$; Figure. $2 \mathrm{~B})$. But there was no significant difference among the group treated with liposome alone, the group treated with SenODNs and the group treated with Mis-ODNs $(P>0.05$; Figure. 2B).

\section{Effect of ATM AS-ODNs on clonogenic survival ability of SCCVII cells after irradiation}

Cellular response to ionizing radiation was evaluated by clonogenic survival assay. Compared with untreated cells or cells treated with control ODNs, cloning efficiency declined notably in cells which transfected with ATM ASODNs at the same dose of radiation (Figure. 3). The survival fraction after 2 Gy (SF2) reflect the cellular intrinsic radiosensitivity. The SF2 of cells transfected with ATM ASODNs was $53.3 \pm 3.1 \%$, definitely lower than that of other cells, which indicated a significant increase in the radiosensitivity $(P<0.05$; Figure. 3$)$. There were no obvious differences among the other groups about clonogenic survival ability $(P>0.05$; Figure. 3$)$.

\section{Effect of ATM AS-ODNs on apoptosis and cell cycle of SCCVII cells after irradiation in vitro}

After 2 Gy irradiation, the apoptotic rate in ATM AS-ODNs transfected cells was $24.7 \pm 2.5 \%$, which was higher than that in Sen-ODNs and Mis-ODNs transfected cells $(P<$ 0.05; Figure. 4). It was also found that cell percentage of G2/M phase was decreased dramatically in ATM AS-ODNs transfected cells at 48 hours after 2 Gy irradiation compared with that of other groups $(P<0.05$; Figure. 5).

\section{Inhibitory effect of ATM AS-ODNs on tumor growth in vivo after irradiation}

In the group treated with ATM AS-ODNs alone and the group irradiated in combination with the treatment of ATM AS-ODNs, the relative ATM protein expression were only $63.4 \pm 5.6 \%$ and $62.1 \pm 6.1 \%$ to the untreated group respectively $(P<0.05$; Figure. 6$)$. Tumor growth of the mice in four groups were shown in Figure. 7 . The inhibition rate in SCCVII cells solid tumor exposed to X-ray alone was $23.2 \pm 2.7 \%$, while it was $56.1 \pm 3.8 \%$ in solid tumor irradiated in combination with the treatment of ATM AS-ODNs at the experimental endpoint $(P<0.05$; Figure. 7).

\section{Enhancement of tumour apoptosis by irradiation combined with ATM AS-ODNs treatment in vivo}

Only small numbers of apoptotic cells were detected by TUNEL analysis in tumors treated with irradiation alone. In contrast with irradiation alone, tumor cell apoptosis was doubled following irradiation in combination with ATM AS-ODNs treatment (Figure. 8A). Accordingly, the AI for tumors from ATM AS-ODNs treated mice was $19.6 \pm$ 3.2 , significantly higher than that of the other groups $(P<$ 0.05; Figure. 8B).

\section{Discussion}

Damage to cellular DNA evokes a wide range of cellular responses that lead to activation of a variety of genes necessary for cellular survival, delay in cell-cycle progression, and induction of DNA repair[18-20]. ATM protein is a key 


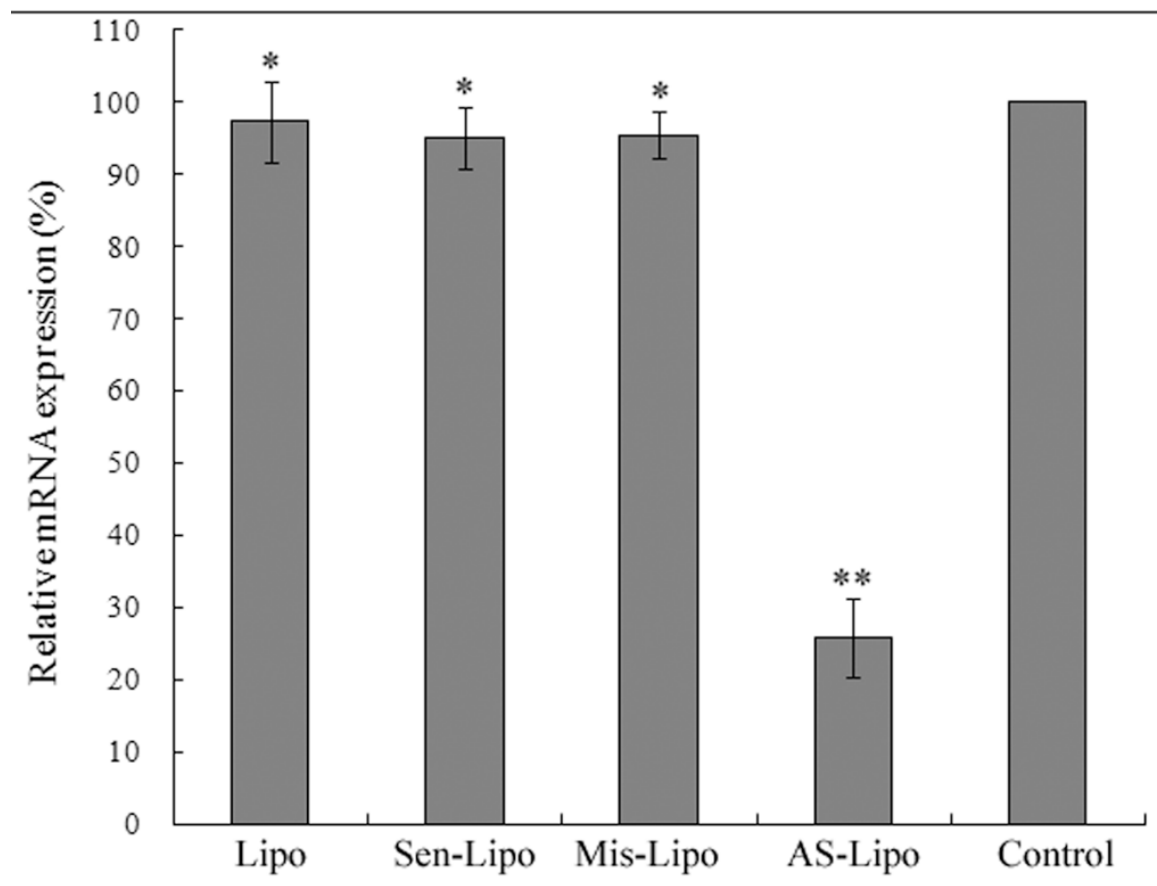

Figure I

Real-time quantitative PCR analysis of ATM mRNA expression. Reduced expression of ATM mRNA in the presence of liposome formulations of ATM AS-ODNs(AS-Lipo) was observed. *P > 0.05, no significantly difference among liposometreated group(Lipo), and Sen-ODNs (Sen-Lipo) treated group and Mis-ODNs (Mis-Lipo)treated group. ${ }^{* * P}<0.05$, compared with other groups.

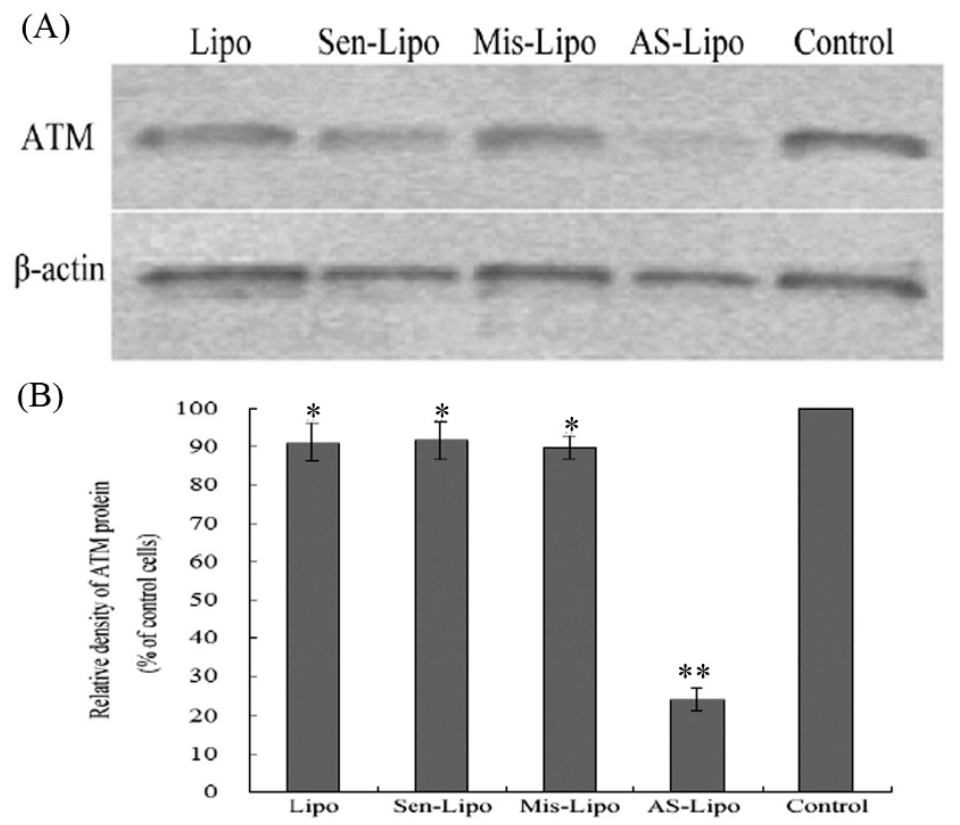

Figure 2

Effect of ATM AS-ODNs on the expression of ATM protein in vitro. (A) Liposome formulations of ATM AS-ODNs significantly reduced the expression of ATM protein compared with other groups. (B) $* P>0.05$, no significantly difference among liposome-treated group(Lipo), and Sen-ODNs (Sen-Lipo) treated group and Mis-ODNs (Mis-Lipo) treated group. **P< 0.05 , compared with other groups. 


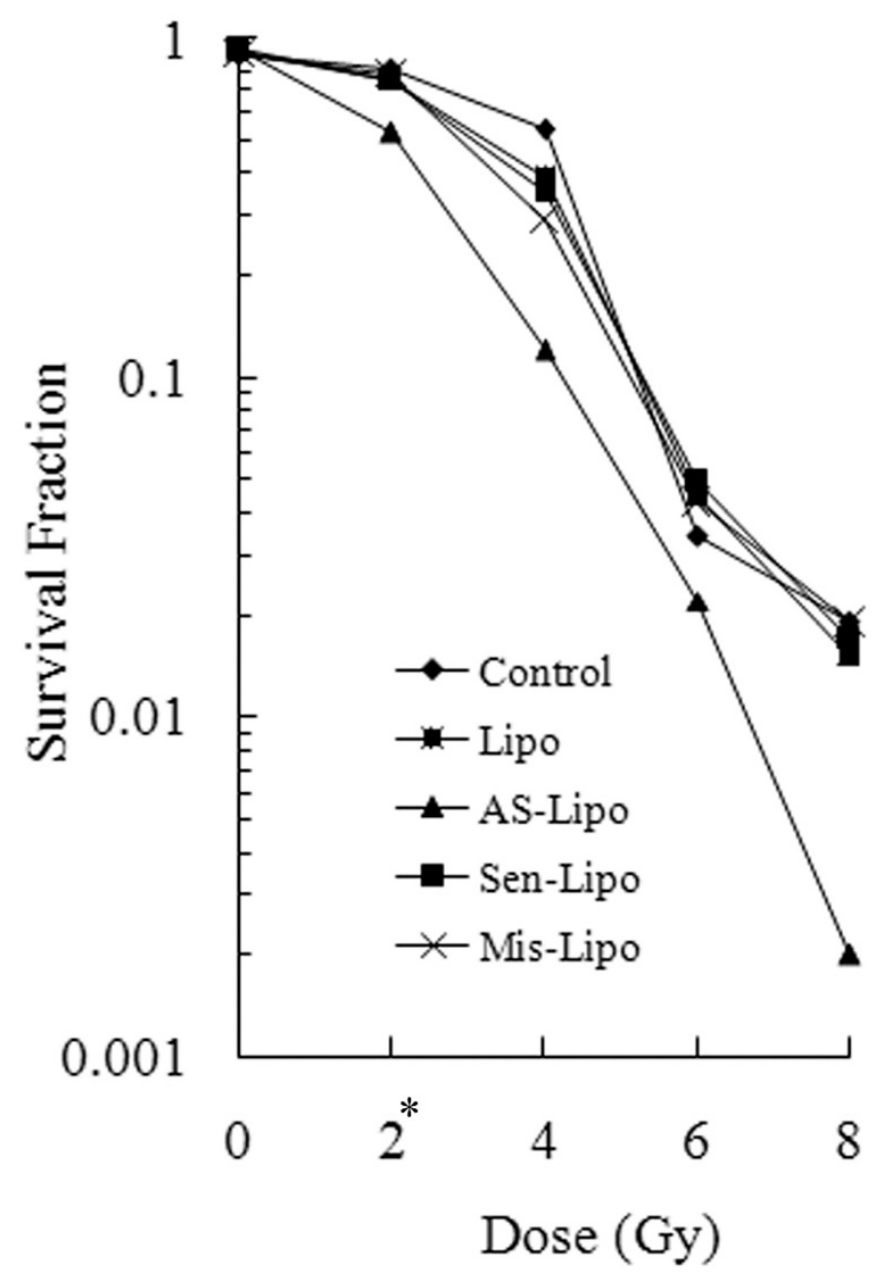

Figure 3

Survival curves for SCCVII cells after irradiation. Survival fractions at each dose point were normalized to untreated cells. $* P<0.05$, The mean of SF2 in the cells transfected with ATM AS-ODNs was significantly lower than that of other cells.

mediator of the radioprotective machinery inducing a signaling network that is responsible for repair of radiationinduced damaged DNA and for cellular recovery and survival [21-23]. Rasheed had found that disruption of the ATM gene in mice resulted in exquisite sensitivity to low doses of ionizing radiation[24]. Yin demonstrated that treatment of mouse cerebrovascular endothelial cells with ATM AS-ODNs led to specific inhibition of ATM induction, and increased radiation-induced apoptosis in vitro[17]. Therefore we designed the experiment to test the hypothesis whether ATM AS-ODNs could inhibit the expression of ATM in SCCVII cells and furthermore increase the radiosensitivity by enhancing radiationinduced apoptosis in vitro and in vivo.

In the present study, we successfully transfected ATM ASODNs into SCCVII cells using liposome as delivery car- rier, and detected the inhibitory expression of ATM at mRNA and protein level in SCCVII cells. We found that expression of ATM was dramatically reduced after cells were transfected with ATM AS-ODNs compared with that Sen-ODNs and Mis-ODNs treated groups, which indicated that the inhibition was specific for the ATM antisense sequence. Then we investigated whether the reduction of ATM expression resulted in radiosensitization in SCCVII cells. The results of clonogenic survival assay in vitro demonstrated that the cloning efficiency declined notably in cells which transfected with ATM ASODNs at the same dose of radiation $(P<0.05)$ compared with untreated cells or cells treated with control ODNs. While the SF2 of cells transfected with ATM AS-ODNs was $53.3 \pm 3.1 \%$, definitely lower than that of other cells, which means the increase of cell intrinsic radiosensitivity. Furthermore we investigated whether the increased radio- 

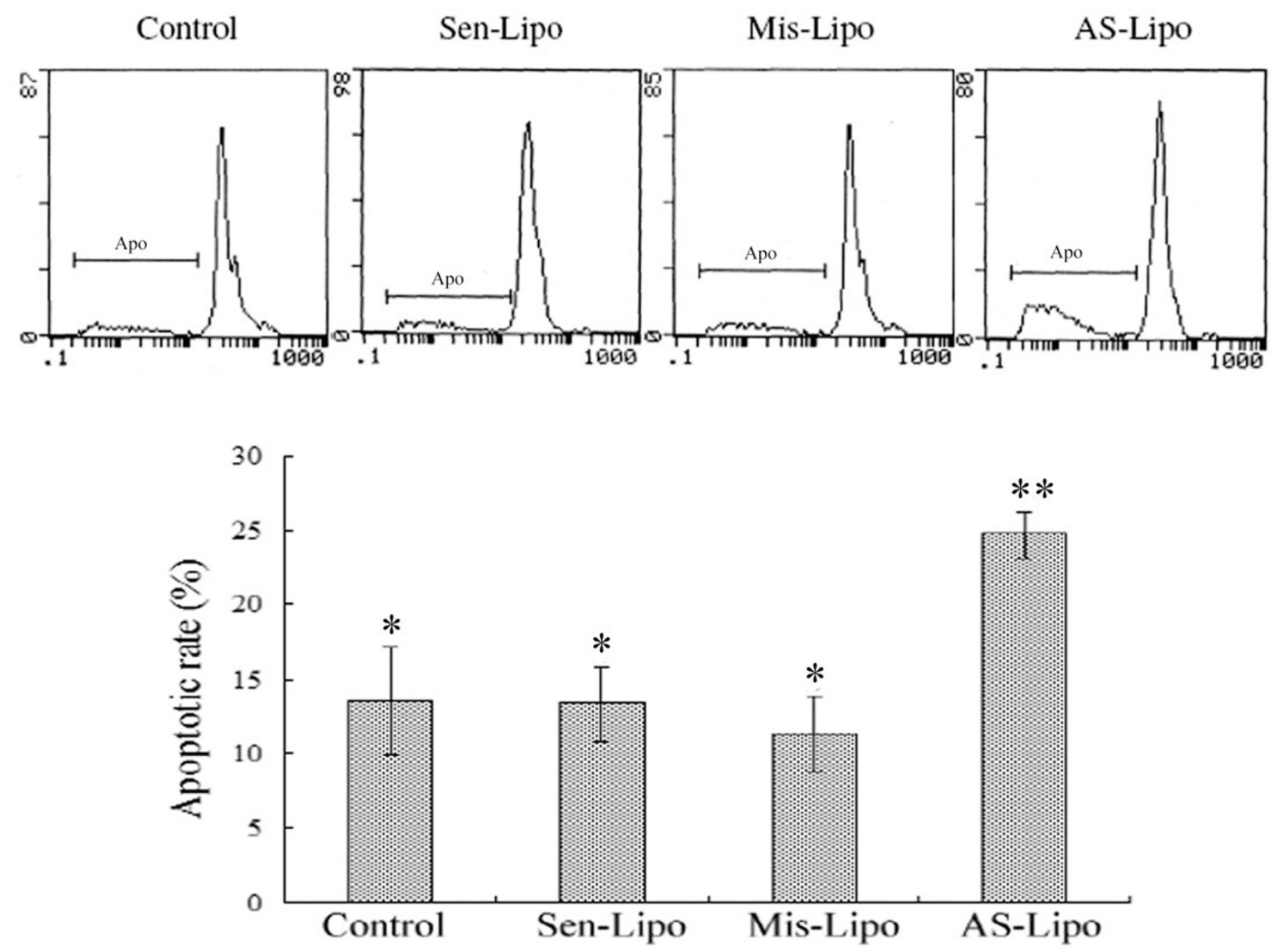

\section{Figure 4}

The apoptotic rate of SCCVII cells after $\mathbf{2}$ Gy irradiation. The apoptotic rate (Apo) in ATM AS-ODNs transfected cells was higher than that in Sen-ODNs and Mis-ODNs transfected cells after 2 Gy irradiation. * $P>0.05$, no significant difference among these groups. $* * P<0.05$, compared with other groups.

sensitivity in SCCVII cells was due to the enhanced radiation-induced apoptosis and defective cell-cycle checkpoint. As we known, in p53 mutated cell lines, ATM mainly regulates the G2/M checkpoint to arrest cells in G2 phase at the time of irradiation where the radiationinduced DSBs can be repaired $[15,16]$. From flow cytometry, we found that the cells did not accumulate in the G2/ $M$ phase following irradiation in cells transfected with ATM AS-ODNs, which mean the reduced ATM expression resulted in the defective G2/M checkpoint control. Moreover, we found that radiation-induced apoptosis increased among the cells lack of ATM expression compared with those cells that have impact ATM expression.
In our study, we also investigated the effects of ATM ASODNs on the apoptotic responses to ionizing radiation in vivo. It was found that the tumors irradiated in combination with the treatment of ATM AS-ODNs were effective in controlling tumor growth and showed higher apoptotic rate. The inhibition rate in the tumors injected with ATM AS-ODNs before exposure to X-ray was $56.1 \pm 3.8 \%$, whereas it was $23.2 \pm 2.7 \%$ in tumors exposed to radiation alone, and a significant difference was found between these two groups $(P<0.05)$. The results of TUNEL assay demonstrated that the apoptotic rate of the tumors irradiated in combination with the treatment of ATM AS-ODNs was obviously higher than that of control groups. The results of in vivo experiments indicated that the radiosensitivity of SCCVII cells solid tumors were enhanced by the 

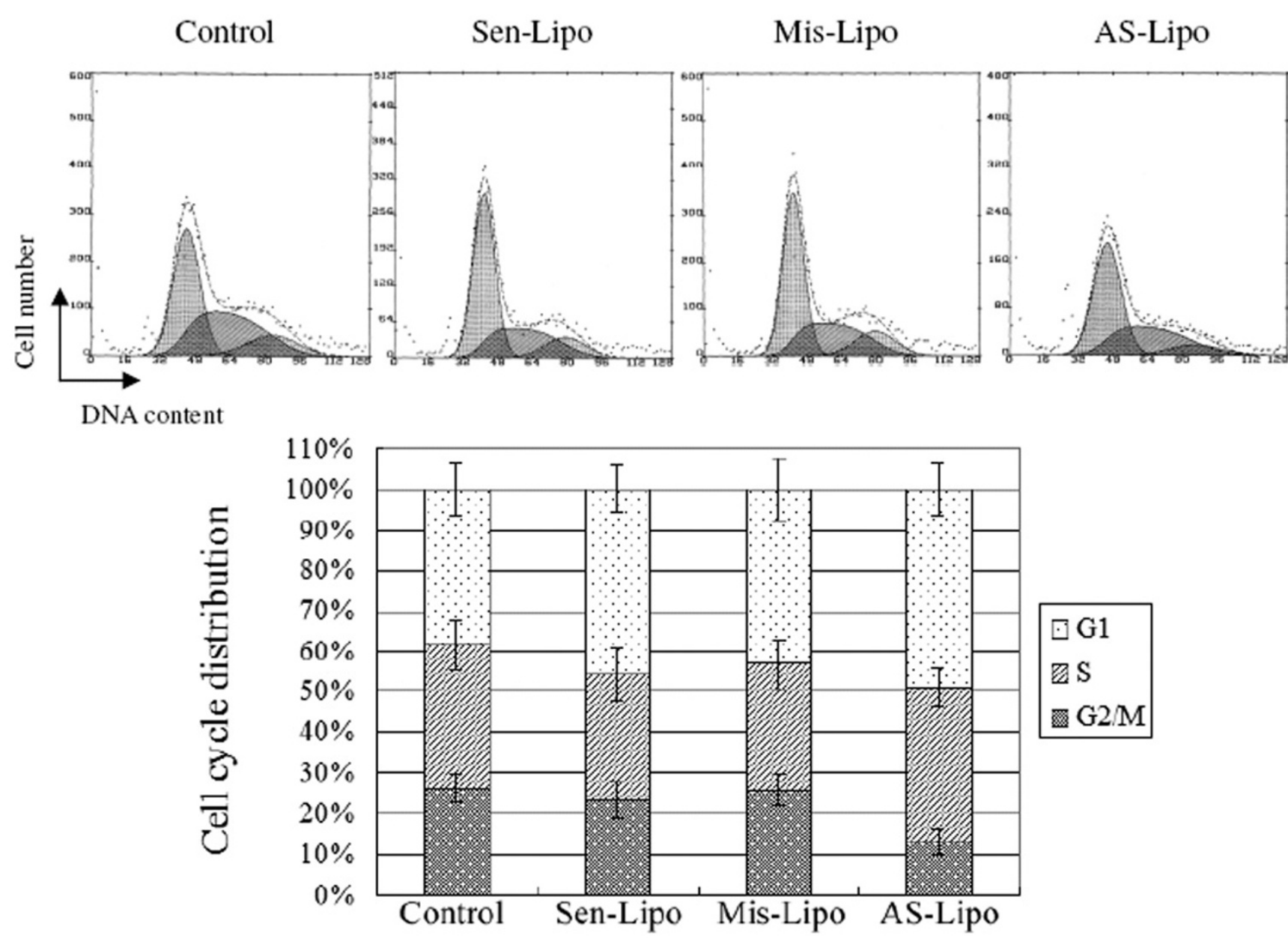

Figure 5

Distribution of the cell cycle in SCCVII cells after 2 Gy irradiation. The cell percentage of G2/M phase decreased dramatically in ATM AS-ODNs transfected cells at 48 hours after 2 Gy irradiation compared with that of other groups $(P<0.05)$.

treatment of ATM AS-ODNs and related with the increased radiation-induced apoptosis.

\section{Conclusion}

We had demonstrated that the ATM AS-ODNs used in our study could specificly reduce the ATM expression and further result in an increased radiosensitivity in SCCVII cells in vitro and in vivo. The potential mechanism of radiosensitization related with reduced ATM expression should be the defective G2/M cell-cycle checkpoint control and enhanced radiation-induced apoptosis.

\section{Competing interests}

The authors declare that they have no competing interests.

\section{Authors' contributions}

XQ carried out cell culture, participated in the design of the study and performed the statistical analysis. HY carried out flow cytometry assay, participated in the animal experiment. YY participated in irradiation for cells and animals. XZ participated in the clonogenic survival assay. HZ carried out the TUNEL assays. SL conceived of the study, and participated in its design and coordination and helped to draft the manuscript. JZ designed the study, per- 


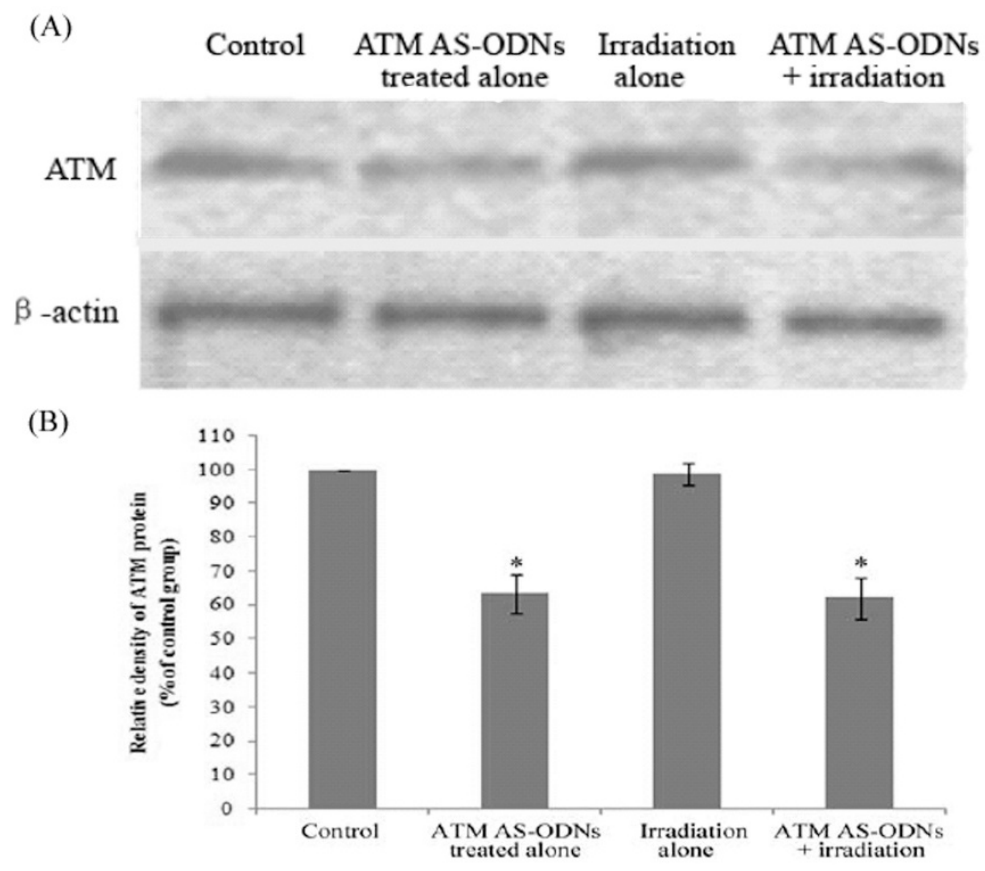

Figure 6

Effect of ATM AS-ODNs on the ATM protein expression in vivo. (A) In the group treated with ATM AS-ODNs alone (ATM AS-ODNs treated alone) and the group irradiated in combination with ATM AS-ODNs (ATM AS-ODNs + irradiation), the expression of ATM protein were decreased. (B) $* P<0.05$, compared with the untreated group and the group irradiated alone.

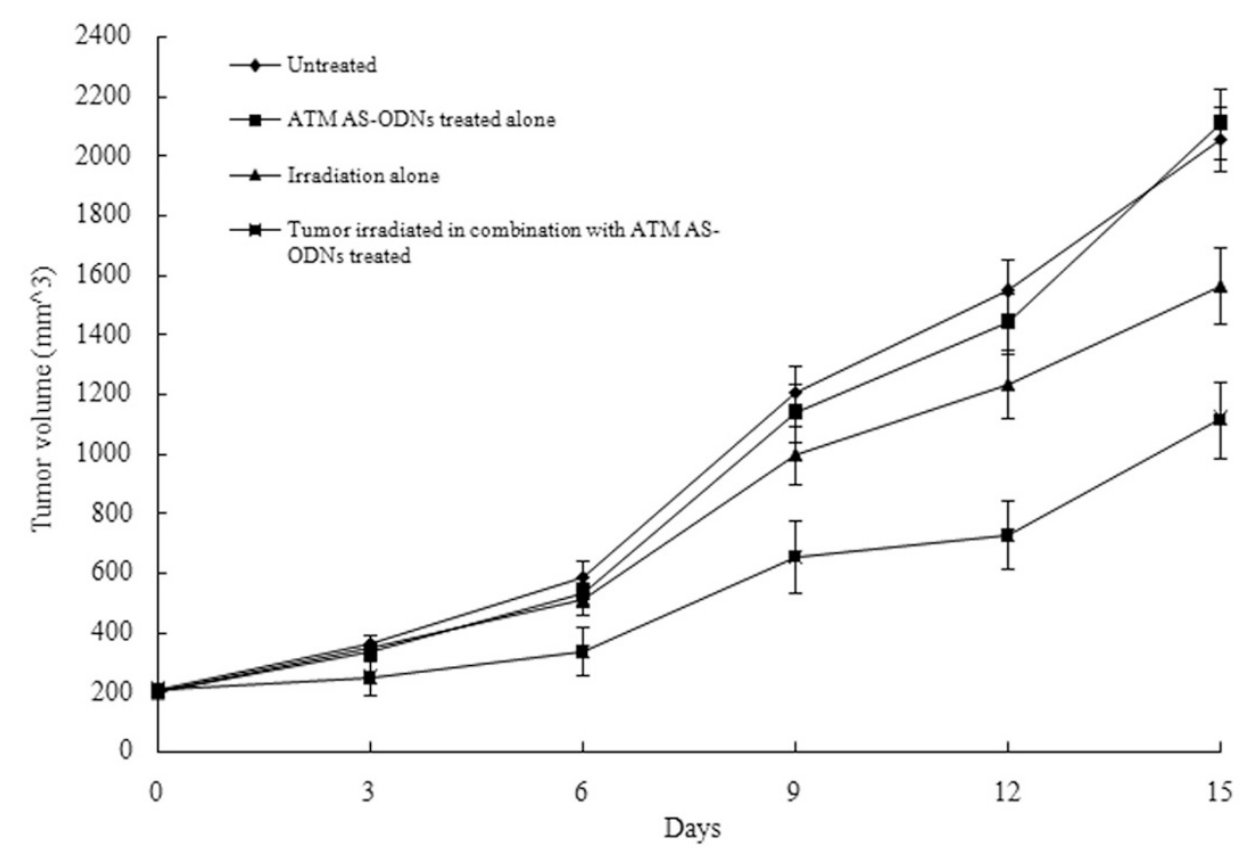

Figure 7

Tumor growth in ATM AS-ODNs treated SCCVII cells in C3H/He mice with or without irradiation. 

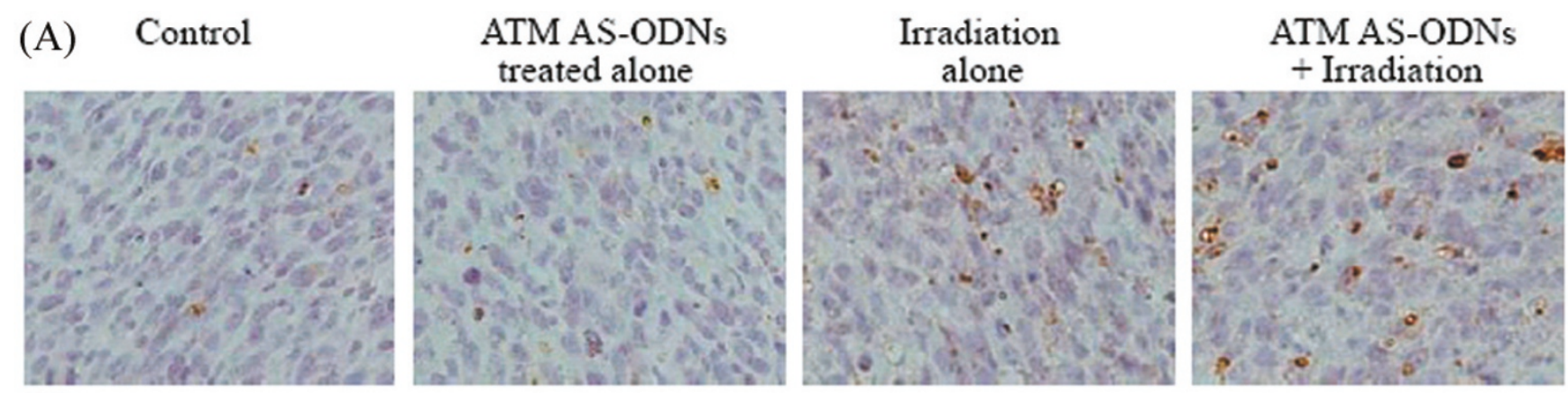

(B)

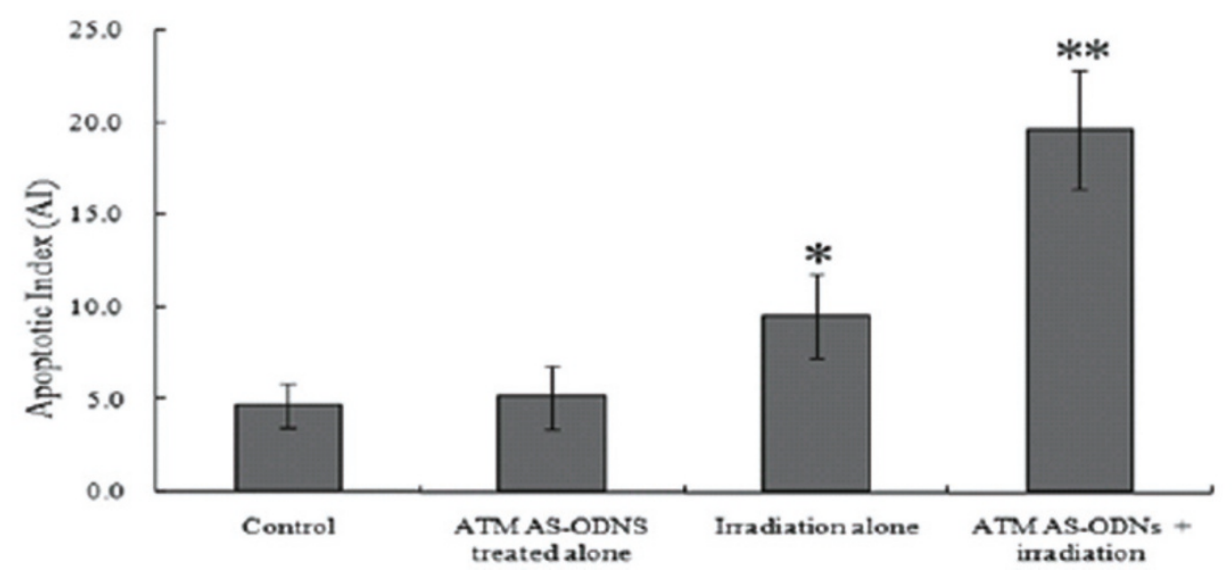

Figure 8

The apoptosis of SCCVII cells in vivo after irradiation. (A) Apoptotic cells are detected by TUNEL. The nuclei of apoptotic cells were stained brown as observed under light microscopy (magnification, $\times 400)$. (B) The treatment by irradiation in combination with ATM AS-ODNs injection enhanced the apoptotic rate of tumor cells. $* P<0.05$, there was a significant difference in the Al of tumors treated with irradiation alone compared with the untreated group and the group treated with ATM AS-ODNs alone. ** $P<0.05$, compared with the other groups.

formed the rest of the experiments and wrote the manuscript. All authors read and approved the final manuscript.

\section{Acknowledgements}

This work was supported by the National Natural Science Foundation of China (No. 305720 I3). We thank the Laboratory of gene therapy at Johns Hopkins University for generous gift of SCCVII cell line. We also thank Dr. Shan Hai (Department of Geriatrics, West China Hospital, Sichuan University, Chengdu, Sichuan, 61004I, China) for correcting English of the manuscript.

\section{References}

I. Rhee JG, Li D, O'Malley BW Jr, Suntharalingam M: Combination radiation and adenovirus-mediated PI6(INK4A) gene therapy in a murine model for head and neck cancer. ORL; journal for oto-rhino-laryngology and its related specialties 2003, 65: 144-54.

2. Rhee JG, Li D, Suntharalingam M, Guo C, O'Malley BW Jr, Carney JP: Radiosensitization of head/neck squamous cell carcinoma by adenovirus-mediated expression of the Nbs I protein. International journal of radiation oncology, biology, physics 2007, 67:273-8.
3. O'Malley BW Jr, Cope KA, Johnson CS, Schwartz MR: A new immunocompetent murine model for oral cancer. Arch Otolaryngol Head Neck Surg 1997, I 23(1):20-24.

4. Khurana D, Martin EA, Kasperbauer JL, et al.: Characterization of a spontaneously arising murine squamous cell carcinoma (SCC VII) as a prerequisite for head and neck cancer immunotherapy. Head \& neck 200I, 23:899-906.

5. Dunne AL, Price ME, Mothersill C, McKeown SR, Robson T, Hirst DG: Relationship between clonogenic radiosensitivity, radiation-induced apoptosis and DNA damage/repair in human colon cancer cells. British journal of cancer 2003, 89:2277-83.

6. Li Y, Carty MP, Oakley GG, Seidman MM, Medvedovic M, Dixon K: Expression of ATM in ataxia telangiectasia fibroblasts rescues defects in DNA double-strand break repair in nuclear extracts. Environmental and molecular mutagenesis 200I, 37:128-40.

7. El-Awady RA, Dikomey E, Dahm-Daphi J: Radiosensitivity of human tumour cells is correlated with the induction but not with the repair of DNA double-strand breaks. British journal of cancer 2003, 89:593-601.

8. Sakata K, Someya M, Matsumoto Y, Hareyama M: Ability to repair DNA double-strand breaks related to cancer susceptibility and radiosensitivity. Radiation medicine 2007, 25:433-8.

9. Shiloh Y: ATM and related protein kinases: safeguarding genome integrity. Nature reviews 2003, 3:155-68.

10. Shiloh Y, Lehmann AR: Maintaining integrity. Nature cell biology 2004, 6:923-8. 
11. Berkovich E, Monnat RJ Jr, Kastan MB: Roles of ATM and NBS I in chromatin structure modulation and DNA double-strand break repair. Nature cell biology 2007, 9:683-90.

12. Peng $\mathrm{Y}$, Woods RG, Beamish H, et al.: Deficiency in the catalytic subunit of DNA-dependent protein kinase causes down-regulation of ATM. Cancer research 2005, 65:1670-7.

13. Morales M, Theunissen JW, Kim CF, Kitagawa R, Kastan MB, Petrini $\mathrm{JH}$ : The Rad50S allele promotes ATM-dependent DNA damage responses and suppresses ATM deficiency: implications for the Mrell complex as a DNA damage sensor. Genes \& development 2005, 19:3043-54.

14. Mirzayans R, Severin D, Murray D: Relationship between DNA double-strand break rejoining and cell survival after exposure to ionizing radiation in human fibroblast strains with differing ATM/p53 status: implications for evaluation of clinical radiosensitivity. International journal of radiation oncology, biology, physics 2006, 66: I498-505.

15. Delia D, Fontanella E, Ferrario C, Chessa L, Mizutani S: DNA damage-induced cell-cycle phase regulation of $\mathrm{p} 53$ and $\mathrm{p} 2 \mathrm{I}$ wafl in normal and ATM-defective cells. Oncogene 2003, 22:7866-9.

16. Gaul L, Mandl-Weber S, Baumann P, Emmerich B, Schmidmaier R: Bendamustine induces $G 2$ cell cycle arrest and apoptosis in myeloma cells: the role of ATM-Chk2-Cdc25A and ATMp53-p2I-pathways. Journal of cancer research and clinical oncology 2008, I 34:245-53.

17. Yin KJ, Chen SD, Lee JM, Xu J, Hsu CY: ATM gene regulates oxygen-glucose deprivation-induced nuclear factor-kappaB DNA-binding activity and downstream apoptotic cascade in mouse cerebrovascular endothelial cells. Stroke; a journal of cerebral circulation 2002, 33:247I-7.

18. Eastham AM, Atkinson J, West CM: Relationships between clonogenic cell survival, DNA damage and chromosomal radiosensitivity in nine human cervix carcinoma cell lines. International journal of radiation biology 200I, 77:295-302.

19. Wada $\mathrm{S}$, Kurahayashi $\mathrm{H}$, Kobayashi $\mathrm{Y}$, et al.: The relationship between cellular radiosensitivity and radiation-induced DNA damage measured by the comet assay. The Journal of veterinary medical science/the Japanese Society of Veterinary Science 2003, 65:47I-7.

20. Wada S, Van Khoa T, Kobayashi Y, et al:: Prediction of cellular radiosensitivity from DNA damage induced by gamma-rays and carbon ion irradiation in canine tumor cells. The Journal of veterinary medical science/the Japanese Society of Veterinary Science 2005, 67:1089-95

21. Savitsky K, Bar-Shira A, Gilad S, et al.: A single ataxia telangiectasia gene with a product similar to PI-3 kinase. Science 1995, 268(5218): 1749-1753.

22. Riballo $E$, Kuhne $M$, Rief $N$, et al.: A pathway of double-strand break rejoining dependent upon ATM, Artemis, and proteins locating to gamma-H2AX foci. Molecular cell 2004, 16:715-24.

23. Lavin MF: The Mre I I complex and ATM: a two-way functional interaction in recognising and signaling DNA double strand breaks. DNA repair 2004, 3:1515-20.

24. Rasheed N, Wang X, Niu QT, Yeh J, Li B: Atm-deficient mice: an osteoporosis model with defective osteoblast differentiation and increased osteoclastogenesis. Human molecular genetics 2006, 15: 1938-48.
Publish with Biomed Central and every scientist can read your work free of charge

"BioMed Central will be the most significant development for disseminating the results of biomedical research in our lifetime. "

Sir Paul Nurse, Cancer Research UK

Your research papers will be:

- available free of charge to the entire biomedical community

- peer reviewed and published immediately upon acceptance

- cited in PubMed and archived on PubMed Central

- yours - you keep the copyright
BioMedcentral 